\title{
Another Look at the Relationship between Portfolio Returns and Market Multiples
}

\author{
Marlena Akhbaria ${ }^{\mathrm{a}}$, M. Fall Ainina ${ }^{\mathrm{b}}$, James E. Larsen ${ }^{\mathrm{c}}$
}

Abstract: Equity investors are always interested in identifying profitable trading strategies. The price-to-earnings ratio $(P / E)$ and price-to-sales ratio $(P / S)$ are two simple metrics that researchers have reported may meet this objective under particular market conditions. During our study period, which is longer in duration than most of the previous works, the performance of portfolios based on $P / S$ dominated those based on $P / E$. However, portfolios based upon the combination of low $P / E$ and net profit momentum outperformed all other strategies tested. Another way the predictive power of $P / E$ may be improved is by dividing it by a measure of the firm's earnings growth, yielding a composite metric known as the price-to-earnings-to-earnings growth ratio (PEG). This metric has gained the attention of professional investors and researchers. Because many investors prefer $P / S$ over $P / E$, it is surprising that a counterpart to $P E G$ has not gained similar traction. Our results provide evidence that helps explain why the price-to-sales-to-sales growth ratio (PSG) has failed to gain attention. Our results also indicate that none of these market multiples alone can be employed to provide consistently profitable investment performance.
Keywords: Holding periods, Portfolio, Portfolio choice, Price-to earnings ratio, priceto-earnings-to-earnings growth ratio, Price-to-sales ratio, Price-to-sales-to-sales growth ratio.

JEL: G11, G23

$\begin{array}{ll}\text { Received } & : 11 \text { March } 2020 \\ \text { Revised } & : 29 \text { April } 2020 \\ \text { Accepted } & : 29 \text { May } 2020 \\ & \\ \text { Type } & \text { : Research }\end{array}$

\section{Introduction}

Equity investors are always on the lookout for profitable trading strategies. Simple existing strategies include using either a low price-to-earnings ratio $(\mathrm{P} / \mathrm{E})$ or low price-to-sales ratio $(\mathrm{P} / \mathrm{S})$ as a stock selection criterion. A potential shortcoming, in either case, is that a firm may have a low $\mathrm{P} / \mathrm{S}$ or $\mathrm{P} / \mathrm{E}$ because it is simply not a very good business, but researchers have demonstrated that the predictive power of either ratio is enhanced when used in combination with other variables. $P / E$ is one of the most, if not the most, published market multiple in the popular press. The Wall Street Journal, Barron's and others have, for decades, routinely included $\mathrm{P} / \mathrm{E}$ in their stock market quotations. On the other hand, $\mathrm{P} / \mathrm{S}$ did not become fashionable until the Internet stock bubble when negative earnings greatly reduced the usefulness of earnings-based multiples (Bajkowski, 2003). P/S has at least two advantages over earnings-based multiples. First, unlike $P / E$, $\mathrm{P} / \mathrm{S}$ can be calculated even when earnings are negative. Second, $\mathrm{P} / \mathrm{S}$ may be a more reliable indicator of firm performance because analysts generally pay more attention to earnings than sales which might provide more motivation for firm managers to manipulate earnings more often than sales. ${ }^{1}$

Assoc. Prof., Wright State University, Department of Finance and Financial Services, Dayton, Ohio, USA, marlena.akhbari@wright.edu (ORCID ID: 0000-0002-9480-6317)

b Prof., Wright State University, Department of Finance and Financial Services, Dayton, Ohio, USA, fall.ainina@wright.edu (ORCID ID: 0000-0002-1722-9931)

Prof., Wright State University, Department of Finance and Financial Services, Dayton, Ohio, USA, james.larsen@wright.edu (ORCID ID: 0000-0001-5978-7133) 
Researchers have reported a significant relationship between future investment returns and both $\mathrm{P} / \mathrm{E}$ and $\mathrm{P} / \mathrm{S}$. ${ }^{2}$ Direct comparison of the predictive power of $\mathrm{P} / \mathrm{E}$ and $\mathrm{P} / \mathrm{S}$ has provided conflicting results. For example, Senchak and Martin (1987) found that low P/E stocks generated superior excess returns compared to ones based on low P/S stocks during 1976-1984, but Nathan, Sivakumar, and Vijayakumar (2001) reported strategies using $\mathrm{P} / \mathrm{S}$ ratios consistently earned higher excess returns than strategies employing $\mathrm{P} / \mathrm{E}$ ratios during 1990-1996. These studies involved non-overlapping study periods and are considerably shorter than the study period in the present study. One of the goals of the present study is to determine if either simple metric dominates the other over a more protracted and recent time frame.

It has been shown that the predictive power of either $\mathrm{P} / \mathrm{E}$ or $\mathrm{P} / \mathrm{S}$ can be improved as a stock selection metric by using them in conjunction with other criteria. Nathan, et al. (2001), for example, showed that trading strategies that combine $\mathrm{P} / \mathrm{E}$ and $\mathrm{P} / \mathrm{S}$ produce results superior to those that rely on either measure alone. Vruwink, Quirin, and O'Bryan (2007) and Barbee, Jeong, and Mukherji (2008) both investigated including profit margins with $\mathrm{P} / \mathrm{S}$ in the stock selection process, and report inconsistent results. Vruwink et al. (2007) found that the combination did not always result in better performance than the simple P/S strategy while Barbee et al. (2008) found that the combination of $\mathrm{P} / \mathrm{S}$ and profitability ratios did have greater explanatory power for returns than the use of $\mathrm{P} / \mathrm{S}$ ratios alone.

An interesting way the predictive power of $\mathrm{P} / \mathrm{E}$ can be improved as a stock selection metric is by dividing it with a measure of the firm's earnings growth, yielding a composite metric known as the price-toearnings-to-earnings growth ratio (PEG). This metric has gained the attention of professional investors (e.g., Ashton, 2002; Hutheesing, 2005; Biondo, 2007; Leeb, 2010) and has been examined by numerous academic researchers (e.g., Gerstein, 2002; Arak \& Foster, 2003; Khattab, 2006; Trombley, 2008; Schatzberg \& Vora, 2009).

Given that many investors appreciate the advantages of $\mathrm{P} / \mathrm{S}$ over $\mathrm{P} / \mathrm{E}$, it is surprising that attempts to develop a P/S-counterpart to PEG have been sparse. A short article appearing on the Seeking Alpha ${ }^{\alpha}$ web site (Backroom Analyst, 2015) introduced the price-to-sales-to-sales growth ratio (PSG), but to date it has failed to gain traction in equity investment circles and has been largely ignored by academic researchers. Therefore, a second objective of this study is to compare PEG and PSG.

This paper reports the results of our analysis of 96 non-overlapping portfolios (16 for each of 6 selection criteria) formulated using more current data occurring over a longer study period (January 2001 through August 2018) than most related previous efforts. A t-test is calculated for each of the 96 portfolios to determine whether each strategy provides a significantly greater annualized return than the annualized return on the S\&P 500. This facilitates comparison of returns generated by portfolios based upon $P / E, P / S$, $\mathrm{P} / \mathrm{E}$ and net profit momentum, $\mathrm{P} / \mathrm{S}$ and net profit momentum, $\mathrm{PEG}$, and PSG. For each of these selection criterion, several alternate portfolio reformation periods (ranging from 2 to 24 weeks) are assumed, and because Anderson and Brooks (2007) found the predictive power of $P / E$ is enhanced if portfolios are restricted to the shares of relatively few firms from the tails of the $P / E$ distribution, we test whether portfolio performance is influenced by extreme values for each of the selection criteria tested here on all US stocks listed on the NYSE, AMEX, and NASDAQ as described below.

The remainder of the paper is organized as follows. The data and methodology are described in the next section. The results are presented in the section 3 , and the last section contains our conclusions.

\section{Data and Methodology}

Stock price data was obtained from Zacks Investment Research ${ }^{3}$ which includes all US stocks listed on the NYSE, AMEX and NASDAQ. Portfolios were created using the Zacks Research Wizard to (1) screen, as described below, for stocks appropriate for each strategy, (2) create a series of non-overlapping portfolios for each strategy and (3) back-test the constructed portfolios. More formally, we use utilize a t-test to test the following hypothesis. 
$\mathrm{H}_{0}$ : None of the investment strategies examined here will provide a significantly greater annualized return than the annualized return on the S\&P 500.

The data available for this study begins January 7, 2000 and continues through August 31, 2018.

In formulating portfolios, some shares were eliminated from consideration based on the following conditions. To be consistent with other users of the Zacks Investment Research data ${ }^{4}$, thinly traded stocks were eliminated by screening for and then removing stocks with low trading volume, defined as less than 50,000 shares during the preceding 20 trading days. In addition, the shares of very small firms (defined as those whose total market value was in the bottom $1 \%$ of all firms in the data were identified and eliminated from consideration. Also consistent with the literature, financial firms were omitted as were any firms with negative accounting values that would lead to meaningless profit margin-based variables. Finally, because institutional investors, particularly mutual funds, are reluctant to buy stocks whose price is below $\$ 5$, any stock with a share price less than $\$ 5$ at the time of portfolio formation was also eliminated. Other researchers, such as Cooper, Downs and Patterson (1999), suggest that this last screen also reduces bid-ask bounce effects.

Each strategy was tested for both optimal portfolio size and holding period because there is evidence in the literature that suggests portfolios of stocks with extreme critical values produce the best results. In their analysis of $P / E$, Anderson and Brooks (2007) found that returns are enhanced if portfolios are restricted to the shares of relatively few firms from the tails of the P/E distribution. Two questions remain (1) does Anderson and Brooks finding apply to any of the selection criteria examined here, and if so (2) how many stocks constitute the extreme. To address these questions, under each investment strategy the portfolio size was varied in separate iterations from 5, 10, 20 and 30 stocks. Long positions were assumed in each portfolio and returns were calculated for non-overlapping 2, 4, 12, and 24-week holding periods (given the length of our study period, longer holding periods would suffer from too few observations for reliable testing).

Recall that one of the main objectives of this study is to compare annualized holding period returns of portfolios formulated based upon $\mathrm{P} / \mathrm{E}$ and $\mathrm{P} / \mathrm{S}$. To illustrate the process employed to accomplish this objective, consider the 2-week holding period, 5 -stock portfolio. First, the 5 firms with the lowest, most recent $\mathrm{P} / \mathrm{E}$ ratio are identified and formed into an equally market-weighted portfolio on January 7,2000 . The portfolio return is calculated at the end of two weeks on January 21, 2000 and a new portfolio of 5 stocks is formed which may, or may not, include stocks from the previous 2-week portfolio. The process continues every two weeks until August 31, 2018. The annualized holding period return is calculated at of the conclusion of the study period. For individual investors, the annualized returns are both before- and after-commission returns as several discount brokerage houses now offer commission free online transactions. A similar process was conducted for each of the other $15 \mathrm{P} / \mathrm{E}$ portfolios and $16 \mathrm{P} / \mathrm{S}$ portfolios.

The other main objective of this study is to compare annualized returns of portfolios formulated using PSG and PEG where PSG equals P/S divided by the average annual sales growth rate for the most recent 5years and PEG equals P/E divided by the average growth rate in EPS over the most recent 3 to 5 years. The same process described above is applied in both cases except that the initial step is to identify stocks with the lowest PSG or PEG value. In addition, we follow the advice of Backroom Analyst (2015) and require that the sales growth rate must be at least five times $\mathrm{P} / \mathrm{S} .^{5}$

To add another dimension to our analysis of PEG and PSG, two additional sets of portfolios each based on two separate criteria are formed. Nathan et al. (2001) and Anderson and Brooks (2006), among others, have shown that the introduction of additional information with market multiples (including $\mathrm{P} / \mathrm{E}$ or $\mathrm{P} / \mathrm{S}$ ) enhances the investment performance of the simple metric. Bernstein (2000) and Bajkowski (2010) suggest excellent candidates include profit margin growth. Therefore, portfolios based on (1) low P/E and high net profit margin momentum, and (2) low $\mathrm{P} / \mathrm{S}$ and high net profit margin momentum are also investigated. Net profit margin momentum is defined as the most recent year's growth rate in net profit margin (net income/sales) divided by the average annual growth rate in net profit margin for the most recent 5 years. The above-described process was followed to formulate portfolios based on either low $\mathrm{P} / \mathrm{S}$ or low 
$\mathrm{P} / \mathrm{E}$ after screening the data to limit the eligible stocks to those issued by firms whose most recent net profit margin momentum was greater than 1 .

\section{Results}

The portfolio return results are summarized in Table 1. To address the first of our objectives, we initially focus on the returns from the two basic selection criteria; $\mathrm{P} / \mathrm{S}$ and $\mathrm{P} / \mathrm{E}$. Examination of columns (1) and (4) will reveal that the annualized returns generated by $P / S$ portfolios outperformed $P / E$ portfolios in all 16 cases. $P / E$ portfolios performed particularly poorly. Nearly half of the $P / E$ portfolios generated a negative return and none significantly outperformed the S\&P index. While none of the $\mathrm{P} / \mathrm{S}$ portfolios generated a negative return, only 6 of the $16 \mathrm{P} / \mathrm{S}$ portfolios outperformed the S\&P index. In no case did either a simple $\mathrm{P} / \mathrm{S}$ or $\mathrm{P} / \mathrm{E}$ portfolio provide the highest return of the six strategies investigated. Taken together, these results are consistent with previous studies that found the $P / S$ ratio was a better selection criterion than the $P / E$ ratio (e.g., Nathan et al., 2001; Vruwink et al., 2007; Barbee et al., 2008), and inconsistent with previous studies that found the opposite (e.g., Senchak \& Martin, 1987; Chou \& Liao, 1996). However, our results strongly suggest that reliance upon either single investment criterion is no guarantee of superior investment performance.

It is worth noting that our examination of profitable trading strategies runs counter to the Markowitz Efficient Market Hypothesis as do all the other works cited here. We are essentially looking for plausible factors that might consistently render excess returns which is not plausible under Markowitz.

Next, we focus on the effect of adding a second criterion to the portfolio selection process. While any number of criteria may be useful for this purpose (logic and previous research indicates that multiple additional criteria rather than a single one may be beneficial), we elected to limit the pool of potential portfolio entrants with a single criterion - those stocks with positive momentum in net profit margin. The results indicate that the incorporation of this criterion with either $\mathrm{P} / \mathrm{S}$ or $\mathrm{P} / \mathrm{E}$ very positively influences portfolio performance. Comparison of columns (2) and (1) will reveal the following. In 13 of 16 cases, the addition of the second criterion yielded portfolios that provided greater returns than those provided by portfolios based solely on $\mathrm{P} / \mathrm{S}$. This combination of selection criteria resulted in more double-digit returns (13 of 16 portfolios) than any other strategy. In 6 cases, it provided the highest return of any of the six strategies, and in 11 of 16 cases, it provided a significantly higher return than the S\&P index.

Examination of columns (5) and (4) will reveal the following. In all 16 cases, the addition of net profit margin momentum yielded portfolios that provided greater returns than those provided by portfolios based solely on $\mathrm{P} / \mathrm{E}$. This combination of selection criteria resulted in double-digit returns in 11 of 16 portfolios. In 9 cases, the portfolios generated using this strategy provided the highest return of any of the strategies investigated, including the highest annualized return, 20.93\% (30 stock, 4 week holding period) of all 96 portfolios. In 10 cases, these portfolios provided a significantly higher return than the S\&P index.

Taken together, these results are consistent with previous studies that found that adding additional variables enhances the performance of portfolios based solely upon a simple criterion. In this experiment, the addition of net profit margin momentum had a more profound effect on $\mathrm{P} / \mathrm{E}$ portfolios than $\mathrm{P} / \mathrm{S}$ portfolios. The results indicate that, compared to either simple metric, a two-variable selection strategy would have improved the probability of successful investment during the study period.

Next, recall that another way to incorporate additional criteria into the selection process is to combine them in such a way as to create a single metric that includes multiple criteria. Here we present the results particular to our second objective. Column (6) contains the returns for the portfolios formed using the previously described PEG criterion. Comparing these values to those in column (4) reveals that in 15 of 16 cases, using PEG instead of simple P/E as the selection criterion results in higher returns. If one stops their analysis at this point, the popularity of PEG seems apparent. However, in none of the 16 cases did a PEG portfolio provide the highest return of the strategies investigated, and no PEG portfolio outperformed the corresponding two-variable P/E-based portfolio. In 6 cases PEG portfolios failed to outperform the S\&P index. 
These results bring into question the wisdom of using PEG (rather than profit margin and P/E in tandem) as an investment strategy.

Table 1. Annualized Returns from Six Strategies (1/07/2000 to 8/31/2018)

\begin{tabular}{|c|c|c|c|c|c|c|c|}
\hline $\begin{array}{l}\text { Holding } \\
\text { Period } \\
\text { in } \\
\text { Weeks }\end{array}$ & $\begin{array}{l}\text { Number } \\
\text { of } \\
\text { Stocks } \\
\text { in } \\
\text { Portfoli } \\
\text { o }\end{array}$ & $\mathrm{P} / \mathrm{S}$ & $\begin{array}{l}\text { (2) } \\
\text { P/S \& Net } \\
\text { Profit Margin } \\
\text { Momentum }\end{array}$ & $\begin{array}{c}\text { (3) } \\
\text { PSG } \\
=\mathrm{P} / \mathrm{S} / \text { Growth in } \\
\text { Sales }\end{array}$ & $\begin{array}{l}\text { (4) } \\
P / E\end{array}$ & $\begin{array}{c}\text { (5) } \\
\text { P/E \& } \\
\text { Net Profit Margin } \\
\text { Momentum }\end{array}$ & $\begin{array}{c}\text { (6) } \\
\text { PEG } \\
=P / E / \text { Growth } \\
\text { in EPS }\end{array}$ \\
\hline 2 & 5 & $2.19 \%$ & $6.77 \%$ & $3.78 \%$ & $-6.13 \%$ & $6.09 \%$ & $3.39 \%$ \\
\hline 2 & 10 & $10.98 \%$ & $10.56 \%$ & $2.90 \%$ & $-2.91 \%$ & $12.81 \%$ & $9.31 \%$ \\
\hline 2 & 20 & $11.84 \%$ & $14.90 \%$ & $3.49 \%$ & $4.16 \%$ & $17.69 \%$ & $10.32 \%$ \\
\hline 2 & 30 & $12.18 \%$ & $14.50 \%$ & $3.53 \%$ & $10.50 \%$ & $18.43 \%$ & $10.21 \%$ \\
\hline 4 & 5 & $4.91 \%$ & $12.19 \%$ & $9.31 \%$ & $-5.30 \%$ & $7.21 \%$ & $4.25 \%$ \\
\hline 4 & 10 & $15.24 \%$ & $13.04 \%$ & $4.34 \%$ & $-1.42 \%$ & $16.14 \%$ & $7.07 \%$ \\
\hline 4 & 20 & $12.68 \%$ & $15.65 \%$ & $5.15 \%$ & $4.90 \%$ & $18.94 \%$ & $10.61 \%$ \\
\hline 4 & 30 & $14.49 \%$ & $18.22 \%$ & $4.67 \%$ & $8.80 \%$ & $20.93 \%$ & $10.29 \%$ \\
\hline 12 & 5 & $0.02 \%$ & $6.81 \%$ & $3.71 \%$ & $-6.49 \%$ & $2.65 \%$ & $2.49 \%$ \\
\hline 12 & 10 & $7.89 \%$ & $12.95 \%$ & $0.64 \%$ & $-3.51 \%$ & $9.51 \%$ & $3.68 \%$ \\
\hline 12 & 20 & $11.06 \%$ & $15.94 \%$ & $2.24 \%$ & $0.21 \%$ & $15.82 \%$ & $6.90 \%$ \\
\hline 12 & 30 & $11.16 \%$ & $14.28 \%$ & $3.91 \%$ & $4.21 \%$ & $17.29 \%$ & $7.01 \%$ \\
\hline 24 & 5 & $4.22 \%$ & $4.16 \%$ & $9.21 \%$ & $-6.59 \%$ & $4.78 \%$ & $3.77 \%$ \\
\hline 24 & 10 & $8.57 \%$ & $13.22 \%$ & $4.82 \%$ & $-2.50 \%$ & $10.74 \%$ & $7.17 \%$ \\
\hline 24 & 20 & $9.31 \%$ & $14.59 \%$ & $5.01 \%$ & $2.13 \%$ & $15.40 \%$ & $6.79 \%$ \\
\hline 24 & 30 & $10.68 \%$ & $13.31 \%$ & $5.13 \%$ & $5.38 \%$ & $16.69 \%$ & $8.03 \%$ \\
\hline
\end{tabular}

Note: The results in bold represent the highest return among all portfolios at each size and holding period.

Column (3) of Table 1 presents the returns for the portfolios formed using the PSG criterion. The extra information included in this composite filter (sales growth) actually reduced the $\mathrm{P} / \mathrm{S}$ predictive power in 12 of 16 cases as evidenced by comparing the values in column (3) and (1). The only portfolios where PSG outperformed P/S were the four with a 2-week holding period. In only 1 of the 16 cases (the 5-stock, 24-week holding period) did a PSG portfolio outperform the S\&P index and provide the highest return of the strategies investigated. This stands in marked contrast to the study reported in Backroom Analyst (2015) which reported that their PSG portfolios provided higher annual returns than the market. Comparing column (3) with column (2) and column (6) will reveal that PSG outperformed the two-variable metric in only 1 of 16 cases and PEG in only 4 of 16 cases. These results provide evidence that helps explain why PSG has failed to gain traction among investors. ${ }^{6}$

Finally, note that for every strategy for any given portfolio reformation period, returns are generally positively related to portfolio size. This is not consistent with what Anderson and Brooks (2007) found with regard to $\mathrm{P} / \mathrm{E}$ in conducting a study similar to the present one (i.e., that returns are enhanced if portfolios are restricted to the shares of relatively few firms from the tails of the selection criterion distribution). 


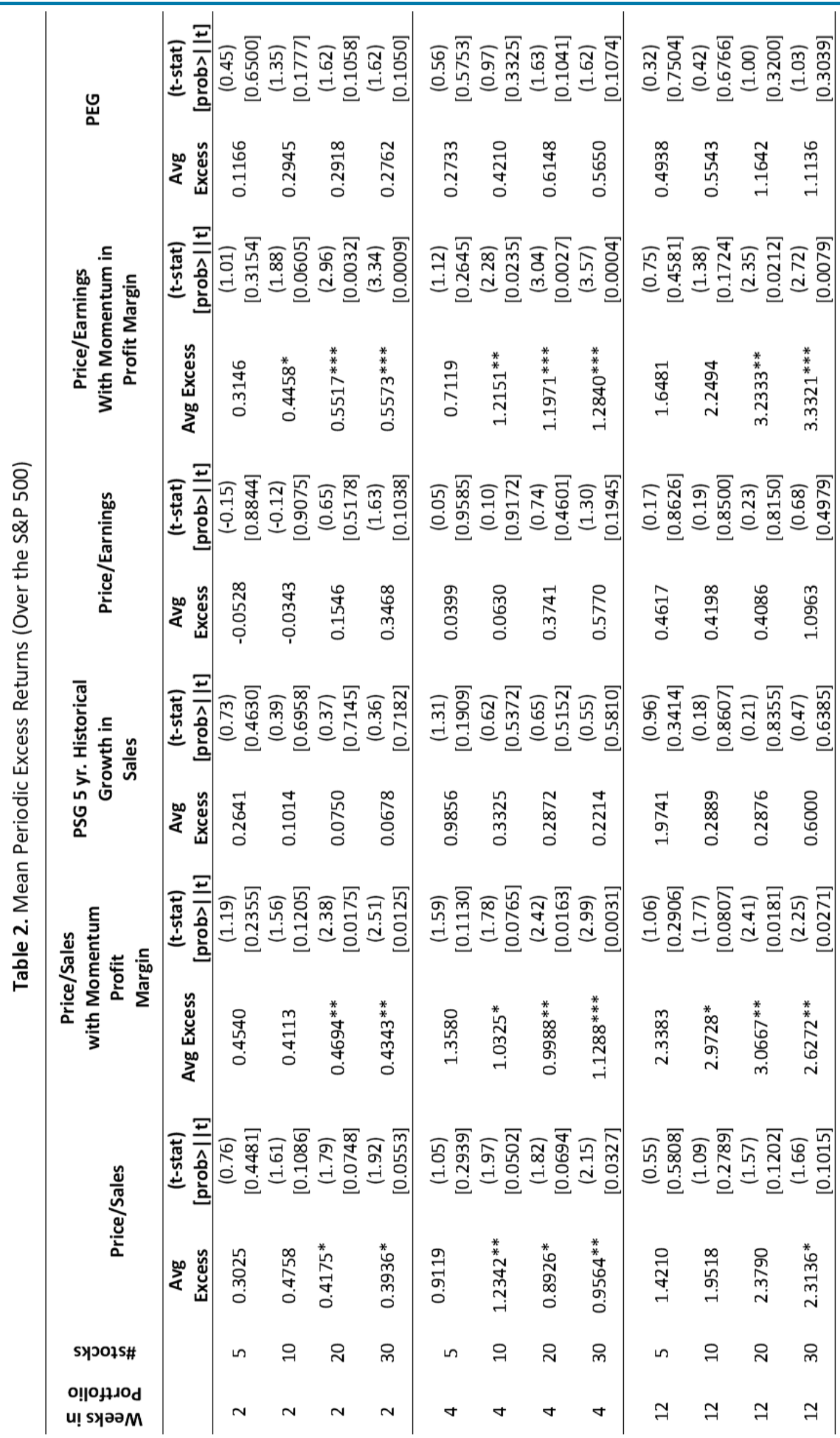




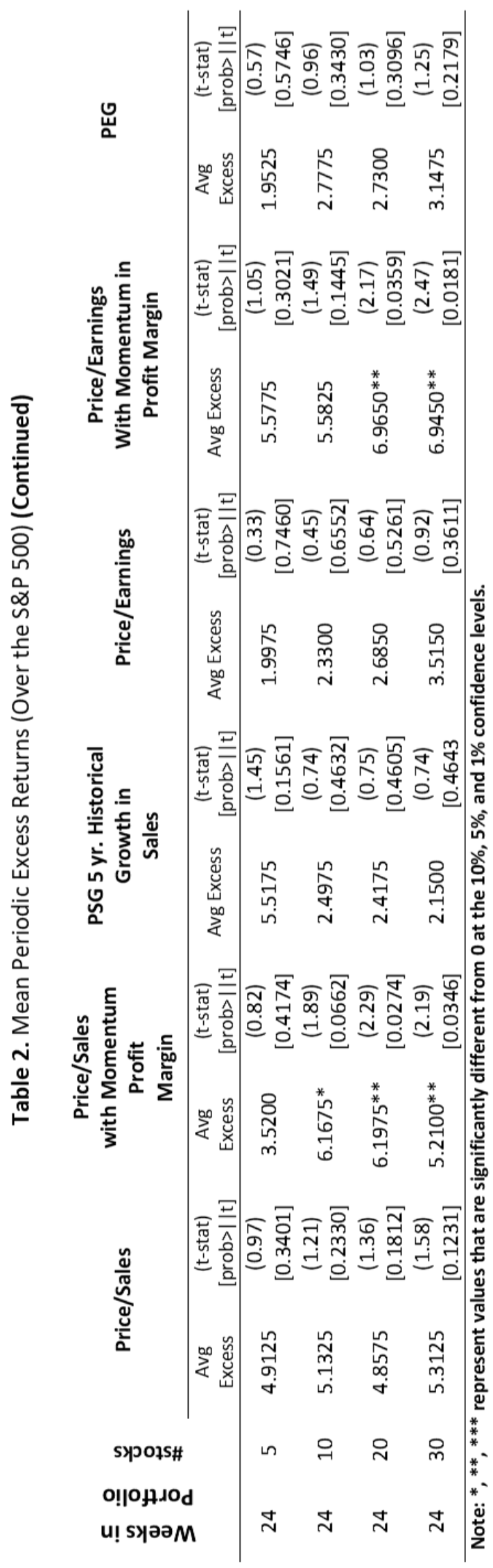


The results presented in Table 2 largely confirm the findings in Table 1 . Table 2 presents mean periodic excess returns for each of the strategies in all portfolio sizes and holding periods using the S\&P as the benchmark. Significance levels are indicated with asterisks. The $P / S$ based results produce excess returns significantly different from zero when the $\mathrm{P} / \mathrm{S}$ ratio is used with the added filter for momentum in profit margins. The returns for 11 of the 16 portfolios using this strategy are significant at some level compared to only 6 out of 16 of the portfolios using a traditional $P / S$ ratio and 0 out of 16 of the portfolios created using the $P / S$ ratio and a filter for growth momentum. The $P / E$ ratio based results follow a similar pattern and outperform the $\mathrm{P} / \mathrm{S}$ based portfolios only when coupled with the filter for momentum in profit margins. The returns for 10 of 16 of portfolios using this strategy are significant, 5 at the $1 \%$ level and 4 at the $5 \%$ level and larger than those based on the similarly constructed portfolios using the $\mathrm{P} / \mathrm{S}$ ratio. None of the portfolios generated using either $\mathrm{P} / \mathrm{E}$ alone of $\mathrm{P} / \mathrm{E}$ with momentum in growth are significant for any size or investment horizon.

\section{Conclusions}

The debate about the relationship between U.S. stock returns and market multiples in the academic literature is long-lived and extensive. Of those studies that compare portfolios formed based upon either $P / E$ or $\mathrm{P} / \mathrm{S}$, most are in agreement with our finding that a $\mathrm{P} / \mathrm{S}$ strategy dominates a $\mathrm{P} / \mathrm{E}$ strategy. None of the $\mathrm{P} / \mathrm{E}$ portfolios in our study generated a return greater than the S\&P 500. Given the success of $P / S$, it is puzzling that PSG has not become as popular as PEG among investors. Our findings are diametrically opposed to those of the pioneering (and only other) study of PSG. In the present study, PSG portfolios severely underperformed portfolios formulated based on simple P/S. In fact, none of the PSG portfolios outperformed the market index. The lack of traction enjoyed by PSG among investors seems less puzzling given these results.

Several other conclusions can be drawn from the results. Regarding portfolio rebalancing frequency in our sample, the four-week rebalancing scheme results in the strongest annualized returns. The results, however, are not consistent with the notion that the biggest benefit comes from the tails of return distributions. In fact, the opposite is generally the case; returns are positively related to the number of stocks comprising the portfolio. The two portfolio types that provided the best returns were those that added a second screen, net profit momentum, to either P/E or P/S. Exclusive use of any of the six strategies examined here remains a risky proposition; only 27 of the 96 portfolios generated annualized holding period returns significantly above the market return. In essence, our study does not allow us to reject the null hypothesis originally set out in this paper.

\section{Disclosure Statements}

1. The authors of this article confirm that their work complies with the principles of research and publication ethics.

2. No potential conflict of interest was reported by the authors.

3. This article was screened for potential plagiarism using a plagiarism screening program.

\section{End Notes}

1. Corporate managers can manage earnings through accruals management and/or by real activities management. Accruals management is accomplished by choosing different accounting methods (e.g., depreciation), which do not alter the firm's economic activities nor have any direct cash flow consequences, to disguise true profitability. Real activities management occurs when managers depart from normal operational practices with the intent to mislead stakeholders into believing certain financial goals have been met in the normal course of operations. Manipulation of real activities normally has direct cash flow consequences (e.g., cutting discretionary expenditures such as maintenance or selling assets). Studies by Cohen et al., (2008) and Zang (2011) are among the scores of papers focused on earnings management which may be of interest to the reader. 
2. Examples of studies focusing on P/E include Nicholson (1960), Basu (1977), Reinganum (1981), Goodman and Peavy (1985, 1986), Senchak and Martin (1987), Yobaccio (1994) and examples of studies focusing on P/S include Fisher (1984), Barbee (1989), Barbee et al. (1996).

3. The Zacks database is growing in popularity with researchers. Notable papers that have used this resource include Barber et al. (2001), Tziogkidis and Zachouris (2009), Ainina et al. (2010), and Wang et al. (2011).

4. See for example, Ainina et al. (2010), and Tziogkidis and Zahouris (2009).

5. According to the Seeking Alphaa web site (Backroom Analyst, 2015), (PSG equals P/S divided by the firm's most recent five-year sales growth rate. The author used PSG to populate equally weighted (regardless of market cap or price) portfolios which were reconstituted monthly from 1997 through 2014. PSG provided higher annual returns than the market.

6. The Backroom Analyst (2015) study differs from the present study in several ways. It did not exclude shares issued by firms with extremely low market capitalization, thinly traded shares, or shares trading at less than \$5. They employed the 5 year growth rate in sales rather than the average annual growth in sales over the most recent 5 years as was done here. Also complicating a comparison of the two studies is the fact that there is no mention of how many firm's shares constitute their portfolios and they only calculate returns based on monthly holding periods.

\section{References}

Ainina, M. F., James, D., \& Mohan, N. (2010). Investment opportunities in zombie stocks. Financial Decisions, 22(2), 115.

Anderson, K., \& Brooks, C. (2007). Extreme returns from extreme value stocks: Enhancing the value premium. Journal of Investing, 16(1), 69-81.

Anderson, K., \& Brooks, C. (2006). Decomposing the price-earnings ratio. Journal of Asset Management, 6(6), $456-469$. Arak, M., \& Foster, R. W. (2003). PEG ratios: What makes sense? Journal of Investing, 12(3), 19-24.

Ashton, Z. (2002). Putting a price on growth. Retrieved on February 23, 2019, from http://www.fool.com/foolish8/2002/foolish8020318.htm

Backroom Analyst, (2015). A New Spin on the Price/Sales Ratio: The PSG Ratio, Seeking Alpha ${ }^{\alpha}$. Retrieved on March 11, 2019 from https://seekingalpha.com/article/3254065-a-new-spin-on-the-price-sales-ratio-the-psgratio?page $=4$

Bajkowski, J. M. (2003). AAll'S low price-to-sales screen: Strong performance in mixed market. AAll Journal, 25(8), 3+.

Bajkowski, J. M. (2010). Low price-to-sales ratio stocks. AAll Journal, 32(9), 16.

Barbee, W. Jr. (1989). Forecasting the performance of a company's common stock with a model based on the sales/price ratio. Spectrum, Fall, 45-49.

Barbee, W. Jr., Jeong, J., \&, Mukherji, S. (2008). Relations between portfolio returns and market multiples. Global Finance Journal, 19(1), 1-10.

Barbee, W. Jr., Mukherji, S., \& Raines, G. (1996). Do sales-price and debt-equity explain stock returns better than bookmarket and firm size? Financial Analysts Journal, 52(2), 56-60.

Barber, B., Lehavy, R. McNichols, M., \& Trueman, B. (2001). Can investors profit from the prophets? Security analyst recommendations and stock returns. Journal of Finance, 56(2) 531-563.

Basu, S. (1977). Investment performance of common stocks in relation to their price-to-earnings ratios: A test of the efficient market hypothesis. Journal of Finance, 32(3), 663-682.

Bernstein, S. (2000). How important is the acceleration or deceleration in growth rates? Bernstein Quantitative Handbook, New York: $\{A / B\}$ Bernstein.

Biondo, J. (2007). Growth investing with PEG analysis. Wall Street Transcript. 177(7), 1+.

Cohen, D. A., Dey, A., \& Lys, T. Z. (2008). Real and accrual-based earning management in the pre-and post-SOX periods. The Accounting Review, 83(3), 757-787.

Chou, P. S. R., \& Liao, T. L. (1996). The relative performance of PER and PSR filters with stochastic dominance: Evidence from the Taiwan Stock Exchange. Applied Financial Economics, 6, 19-27.

Cooper, M., Downs, D. H., \& Patterson, G. A. (1999). Real estate securities and filter-based, short-term trading strategy. Journal of Real Estate Research, 18(2), 313-333.

Fisher, K. (1984). Super Stocks. Homewood, Illinois: Dow Jones-Irwin. 
Gerstein, M. H. (2002). The PEG ratio: Fact and fiction - a mathematically incorrect ratio that can enhance your investment success. Retrieved on March 12, 2019 from http://marketwatch.multexinvestor.com/article.asp?docid=10485

Goodman, D., \& Peavy, J. (1985). The risk universal nature of the P/E effect. Journal of Portfolio Management, 11(4), 1416.

Hutheesing, N. (2005). Wireless app fever. Forbes, 175(12), 3+.

Khattab, J. (2006). How useful is the PEG ratio? Retrieved on March 16, 2019 from http://www.fool.com/investing/value/2006/04/06/how-useful-is-the-peg-ratio.aspx

Leeb, S. (2010). Investing in large cap growth \& resource-oriented stocks. Wall Street Transcript, 183(14), 54-59.

Nathan, S., Sivakumar, K., \& Vijayakumar, J. (2001). Returns to trading strategies based on price-to-earnings and priceto-sales ratios. Journal of Investing, 10(2), 17-28.

Nicholson, S. F. (1960). Price-earnings ratios. Financial Analysts Journal, 16(4), 43-45.

Reinganum, M. R. (1981). Misspecification of capital asset pricing: Empirical anomalies based on earnings' yields and market values. Journal of Financial Economics, 9(1), 19-46.

Schatzberg, J. D., \& Vora, G. (2009). PEG investing strategy: A revisit. Quarterly Journal of Finance and Accounting, 48(2), 5-22.

Senchack, A. J., \& Martin, J. D. (1987). The relative performance of the PSR and PER investment strategies. Financial Analysts Journal, 43(2), 46-56.

Trombley, M. A. (2008). Understanding the PEG ratio. Journal of Investing, 17(1), 22-25.

Tziogkidis, P., \& Zachouris, P. (2009). Momentum equity strategies: Are certain firm-specific variables crucial in achieving superior performance in short term holding periods? International Research Journal of Finance and Economics, 24, 7-27.

Vruwink, D. R., Quirin, J. J., \& O’Bryan, D. (2007). A modified price-sales ratio: A useful tool for investors? Journal of Business \& Economics Research, 5(12), 31-40.

Wang, C., Larsen, J. E., Ainina, M. F., Akhbari, M. L., \& Gressis, N. (2011). Why the dogs of the Dow bark loudly in China. American Journal of Economics and Business Administration, 3(3), 560-568.

Zang, A. (2012). Evidence on the tradeoff between real activities manipulation and accrual-based earnings management. The Accounting Review, 87(2), 675-703. 